\title{
Impact of COVID-19 on Neurosurgery in LMIC: Training and Service Delivery in a Tertiary Care Hospital in Pakistan
}

\author{
Rupesh Raut ${ }^{1} \quad$ Shahzad Shams ${ }^{1} \quad$ Muddassar Rasheed ${ }^{1} \quad$ Azam Niaz $^{1}$ Waqas Mehdi \\ Ammar Bin Ahsan ${ }^{1}$ Shahzaib Tasdique ${ }^{1}$ Adnan Qasim¹ Zainab Sarwar $^{1}$
}

\author{
${ }^{1}$ Department of Neurosurgery, King Edward Medical University, \\ Mayo Hospital, Lahore, Pakistan
}

Indian J Neurotrauma:2021;18:93-94

It is not very uncommon to see the outbreak of contagious diseases in low- and middle-income countries. In Pakistan alone, we have been observing various viral outbreaks such as dengue, chikungunya, and HIV. With the emergence of the coronavirus in Wuhan of Hubei Province in China at the end of December 2019, little have we thought that it will spread like a bushfire across the world and create a pandemic. At the time of writing, the total confirmed cases all over the world are 13,378,853 and 580,045 deaths and in Pakistan, there are 257,914 confirmed cases and 5,426 deaths. ${ }^{1}$ The very first confirmed case of coronavirus disease 2019 (COVID-19) in Pakistan was on February 26, 2020, in Sindh Karachi. ${ }^{2}$ Cases started to get reported in Lahore and other provinces too from the second week of April. Coincidentally World Health Organization (WHO) declared COVID-19 as a pandemic on March 11, 2020, the same day the first case was seen in Lahore. ${ }^{3}$ COVID-19 has not only affected multiple aspects of day-to-day life but has also collapsed the administrative and economic aspects of several nations. The healthcare system is the most affected. This pandemic has brought about various changes in medical practice throughout different specialties including neurosurgery.

Mayo Hospital in Lahore is a teaching hospital affiliated to King Edward Medical University. It is a governmental tertiary care center and a final referral hospital for other hospitals in the province. The service delivery of the whole hospital had to be restructured and reorganized amidst this crisis. Accident and emergency block used to receive medical and surgical emergencies in the same building. Surgical emergency service was relocated to another building to decrease the number of possible exposures to the virus.

Our neurosurgical department had two different wings. The elective wing used to house all our nonemergent patients and had 23 beds with 8 bedded intensive care unit (ICU). Since March 25, 2020, as the number of cases started
Address for correspondence Rupesh Raut, MD, Department of Neurosurgery, King Edward Medical University, Mayo Hospital, Lahore 54000, Pakistan (e-mail: rupexion@yahoo.com).

to rise exponentially in the state, this wing has been converted by the hospital administration to one of the COVID19 wards and positive patients are being placed there and being managed. The emergency wing is present in the accident and emergency block and contains 28 beds. It houses trauma patients and other patients who require emergency neurosurgical care. Neurosurgical ICU is in the same wing with eight beds. We are left with 36 beds only at the moment to take care of our patients.

Before the pandemic, we used to have one consultant, one senior registrar, three resident doctors, and a house officer on call, a total of six doctors at a time. Duty hours ranged from 48 to 56 hours in a week. They used to look after both emergency and elective wing patients with at least two grand rounds in a day with the consultant. We had to decrease the number of on-call doctors to one consultant and two resident doctors at a time and number of duty hours to 24 to 30 hours a week. Neurosurgical doctors are not providing duty in the elective wing as previously but are giving round-the-clock service in the emergency wing.

Emergency consultations alone ranged from 550 to 650 with 130 to 160 admissions in a month in the emergency wing. This has pretty much remained the same during the pandemic as well. Admission in the elective cases is zero because of the new arrangement. We used to operate around 48 to 60 elective cases monthly in our elective theater previously. This number has come down to almost zero. Elective patients seeking emergency care get services from emergency theater when needed. The number of emergency cases undergoing operations ranged from 60 to 80 cases previously. There is no significant change in this number during this crisis too.

Unfortunately, there is no protocol yet to do the screening of patients. Neither swab is taken for reverse transcription polymerase chain reaction nor screening is done through published online

September 14, 2020
Dol https://doi.org/

$10.1055 / \mathrm{s}-0040-1716422$ ISSN 0973-0508.
(C2020. Neurotrauma Society of India.

This is an open access article published by Thieme under the terms of the Creative Commons Attribution-NonDerivative-NonCommercial-License, permitting copying and reproduction so long as the original work is given appropriate credit. Contents may not be used for commercial purposes, or adapted, remixed, transformed or built upon. (https://creativecommons.org/licenses/by-nc-nd/4.0/).

Thieme Medical and Scientific Publishers Pvt. Ltd. A-12, 2nd Floor, Sector 2, Noida-201301 UP, India 
rapid diagnostic tests. High-resolution computed tomography is also not done. Surgery is being done by the consultant, a resident, and a scrub nurse with an anesthesiologist, a circulating nurse, and an operation theater technician in the operating room. Total operating time is being reduced. We are not using high-speed drills for a craniectomy. We are going with good old Hudson brace and Gigli saw with a guidewire for bony work. We cannot do away with the use of electrocautery to reduce the aerosolization. That being said, there is also not a practice to use face shields. The only extra precautionary measures being applied during surgery is the use of double surgical gloves and an N95 mask. Equipment such as face shields, rubber boots, and a full gown that belong to WHO personal protection equipment level 3 are not in use as of now.

During the ward rounds, the number of doctors is reduced to three only. Extensive teaching activities are not performed these days during rounds. Most of the communications between other consultants and residents take place through WhatsApp. The only extra precautionary measure taken during rounds is N95/KN95 masks. The number of attendants with patients is limited to one at a time. Temperature is being checked at the main entrance of the ward before letting anyone in. There is no provision of screening the admitted patients as long as they are asymptomatic for COVID-19.

Previously, we used to have a grand clinical meeting, journal club, morbidity, and mortality meeting once a month. None of these activities are being held since the start of this pandemic. Similarly, we used to have an academic class called "Greenberg Hour" every Tuesdays, three times a month, and neuroanatomy class called "Rhoton Hour" once a month.

Our department has moved on toward virtual videoconferencing through Zoom. These days we are regularly organizing Greenberg hour (academic classes) every Monday and Rhoton hour (neuroanatomy classes) every Thursday. These classes run for about one and a half hours and are attended by almost all the consultants and residents. Even though the link is public and anyone with it can access it, these classes are strictly being conducted for the doctors of our department alone. Most of the residents, along with some senior registrars and consultants, have started to attend multiple national and international webinars on neurosurgery. These webinars have proved to be a good source of knowledge update.
At the time of writing, three of our residents, two senior registrars, and some of their family members are diagnosed with COVID-19. All of them are in self-isolation at their respective homes. Their symptoms range from mild to moderate. Upon asking, most of our residents agree that this sudden change in the running work plan brought about by COVID-19 has created stress in them. A study revealed depression and economic losses in almost 30\% of the neurosurgeons in the subcontinent. ${ }^{4}$ Friends and family getting sick, fear of oneself getting infected, restriction in meet-ups, and social activities all contribute to an increase in the stress level.

This is a difficult time for us, for all the other doctors and the rest of the world. Everyone is trying to adjust to the turmoil caused by this pandemic. To date, no antiviral drugs are known to be effective in its treatment and no vaccine has passed all the phases of clinical trial and ready to be used. Till then, we will have to organize and adjust ourselves with this restructured healthcare system. We need to support each other and continue doing what we are best at. We think that there will be a huge number of piled up elective cases once the pandemic is over. The workload will be huge during that time and we should be ready with a proper plan as early as possible.

\section{Conflict of Interest}

None declared.

\section{References}

1 World Health Organization. Coronavirus Disease (COVID-19) Dashboard. Available at: https://covid19.who.int/region/emro/ country/pk. Updated 16 July 2020. Accessed 17 July 2020

2 Waris A, Atta UK, Ali M, Asmat A, Baset A. COVID-19 outbreak: current scenario of Pakistan. New Microbes New Infect 2020;35:100681

3 Timeline WHO. - COVID-19. Available at: https://www.who. int/news-room/detail/27-04-2020-who-timeline-covid-19. Published 27 April 2020. Accessed 17 June 2020

4 Deora H, Mishra S, Tripathi M, et al. Adapting neurosurgery practice during the Covid-19 pandemic in the Indian subcontinent. World Neurosurg 2020;S1878-8750(20)31549-7. Doi: 10.1016/j.wneu.2020.07.038 